\title{
Ventriculoperitoneal Shunt: Impact of Nursing Management on Outcomes of Patients with Adult Hydrocephalus
}

\author{
Rasha Ali Ahmed Abdelmowla ${ }^{1 *}$, Abdelhakeem A. Essa ${ }^{2}$ \\ ${ }^{l}$ Department of Medical-Surgical Nursing, Faculty of Nursing, Assiut University, Egypt \\ ${ }^{2}$ Department of Neurosurgery, Faculty of Medicine, Assiut University, Egypt.
}

*Corresponding Author: Rasha Ali Ahmed Abdelmowla, Department of Medical-Surgical Nursing, Faculty of Nursing, Assiut University, Egypt. Email: rashaali249@yahoo.com

\begin{abstract}
Background: Hydrocephalus is less common in adults but is complex disorder requiring immediate management.
\end{abstract}

Aim: Evaluate the impact of nursing management on outcomes of patients with adult hydrocephalus treated by ventriculoperitoneal shunt.

Patients and methods: Randomized controlled trial. A random sample of 74 adult male and female through a period of 2 years, their age (18- 65 years), newly diagnosed with adult hydrocephalus and planned for treatment with ventriculoperitoneal shunt in neurosurgery department at Assiut Neurological, Psychiatric and Neurosurgery University Hospital. Randomly, there were 2 groups of patients "Al" and "BI". Group "A1" received routine care provided by hospital while group "BI" received routine care in addition to nursing management by researchers.

Tools: Patients`assessment sheet, knowledge assessment questionnaire, Grading Scale of Japanese Normal Pressure Hydrocephalus, Rand short form 36 items questionnaire, Instructions and exercises logbook and teaching booklet.

Results: Group "B1" showed significant improvements in gait, cognitive function, and quality of life and presented with fewer or no clinical presentations and complications than group "Al".

Conclusion: Continuous nursing management combined with periodic follow up is essential to improve patients`outcomes.

Keywords: Adult hydrocephalus, Nursing management, Outcomes, Ventriculoperitoneal shunt

\section{INTRODUCTION}

Hydrocephalus is a build-up of cerebrospinal fluid within the brain ventricles. It results from disturbance of production, flow or absorption of cerebrospinal fluid (CSF) resulting in increase pressure within the brain ventricles or subarachnoid space (Toma, 2018). Hydrocephalus is called obstructive/non-communicating when caused by blockage of CSF flow in the ventricular system but when caused by inadequate reabsorption of CSF is called non-obstructive/communicating hydrocephalus. Old adults can primarily affected by a form of hydrocephalus called normal pressure hydrocephalus; despite the excess fluid, cerebrospinal fluid pressure is often within normal range (Sivagnanam and Jha, 2012; Nassar and Lippa, 2016).

Non-communicating and communicating hydrocephalus were associated with elevated intracranial pressure, which is responsible for the similar symptoms in both types. However, symptoms may vary slightly depending on the type of hydrocephalus, age of onset and severity (Sivagnanam and Jha, 2012).

International incidence of adult hydrocephalus is unknown. Nearly 100,000 shunts are implanted each year in the developed countries for all age groups of patients, but little information is available for other countries (Nelson, 2016). Also, between 3000 and 3500 shunt operations are performed in United Kingdom yearly, affecting a wide range of patients with both congenital and acquired hydrocephalus (Jenkinson et al., 2014). During 2015, 40 shunt operations are performed for patients with adult hydrocephalus in neurosurgery department at Assiut Neurological, Psychiatric and Neurosurgery University Hospital (Assiut University Hospital Records, 2015). 
Clinical manifestations of adult hydrocephalus include headache, nausea, vomiting, blurred vision, impaired vision, unsteady walk or gait, leg weakness, loss of coordination/balance, irritability, drowsiness, change in personality and behavior, seizures, difficulty in remaining awake or waking up, problems with attention and frequent urination/urgency or incontinence (Witiw et al., 2017; Jaraj, 2016 ).

Symptoms of patients with adult hydrocephalus bring them to medical attention. After a thorough neurological assessment, all patients undergo a computed tomography scan or magnetic resonance scan. Brain ventricles are enlarged in most forms of hydrocephalus. In addition, scans can sometimes show the underlying cause of adult hydrocephalus (American Association of Neurological Surgeons, 2018).

All types of hydrocephalus require early detection and treatment to minimize or prevent long-term problems. Untreated hydrocephalus can lead to death as a result of tonsillar herniation secondary to raised intracranial pressure with compression of the brain stem and subsequent respiratory arrest (Roytowski and Figaji, 2013).

Shunting procedure is the treatment of choice to equalize pressure, minimize/prevent brain damage as a result of increased intracranial pressure and reduce manifestations of neurological deterioration. The most common type of shunt is ventriculoperitoneal shunt; catheter is inserted into brain ventricle, which is connected to valve and a long catheter which diverts cerebrospinal fluid to the peritoneal cavity where it reabsorbed (Sotelo, 2012).

Regardless the high rate of ventriculoperitoneal shunt complications, it stills the mainstay of management for hydrocephalus. Shunt malfunction, shunt infection, over drainage, under drainage, peritonitis, hernia, lost distal catheter, bowel perforation and subdural hematoma all are complications of ventriculoperitoneal shunt (Rinker et al., 2015).

Thorough assessment of health history, clinical presentations, neurological status and vital signs is the responsibility of the nurse. Nurses should be alert to any changes in patient's physical and cognitive functions, check patient's skin for redness along shunt site, implement seizure precautions, minimize stimuli and provide privacy. Nurses need to monitor the patient for any shunt complications. If any complications occur, nurses need to act immediately because delayed response can have dire consequences for the patient (Parsons et al., 2016; Ferguson et al., 2007).

Shunt complications can occur any time. So, patient should be informed with shunt complications and with manifestations that indicate occurrence of these complications including redness, tenderness, pain or swelling of the skin along the length of the tube or incision, irritability, drowsiness, nausea, vomiting, headache, double vision, fever, abdominal pain or return of preoperative neurological symptoms. Stress the importance of reporting any complications/ symptoms that may occur after discharge to nurses or neurosurgeons to receive prompt and early management (Anderson and Chumas, 2012).

Ventriculoperitoneal shunt complications usually require another operation to make a surgical revision of the shunt. Depending on the cause of the complications, some or all of the components of the shunt will be replaced. In the event of infection, the patient is given a course of antibiotic and the entire shunt is replaced (Khan et al., 2015).

Because of hydrocephalus is an ongoing condition, short and long-term care is required. Physical training exercises considered the important part of the rehabilitation process. However, recovery may be limited by the extent to which damage caused by the hydrocephalus and brain ability to heal. Follow-up diagnostic tests including computed tomography scan, magnetic resonance imaging and X-ray, are helpful in determining if the ventriculoperitoneal shunt is working properly (Lehnert et al., 2011; Chen et al., 2009).

So, we conducted this study to enhance clinical outcomes for those patients; improve gait, cognitive function, and quality of life and reduce or prevent complications/clinical presentations.

\section{AIM OF THE STUDY}

Evaluate the impact of nursing management on outcomes of patients with adult hydrocephalus treated by ventriculoperitoneal shunt.

\section{Research Hypothesis}

Group "B1" will show significant improvements in gait, cognitive function, and quality of life and presented with fewer or no clinical presentations/complications than group "A1". 


\section{Outcomes Measures}

Japanese Normal Pressure Hydrocephalus Grading Scale (gait disturbance, cognitive impairment and urinary disturbance), Rand short form 36 items questionnaire (quality of life), clinical presentations and postoperative complications.

\section{Patients and Methods}

Randomized controlled trial research design was used to conduct our study. A random sample of 74 adult male and female patients through a period of 2 years, their age ranged from 18- 65 years, newly diagnosed with adult hydrocephalus and planned for treatment with ventriculoperitoneal shunt in neurosurgery department at Assiut Neurological, Psychiatric and Neurosurgery University Hospital. Randomly, there were 2 groups of patients "A1" and "B1" [single number = group "A1" and double number $=$ group "B1"]. Unconscious patients, patients with surgical procedures other than ventriculoperitoneal shunt or those with previous history of ventriculoperitoneal shunt were excluded. Group "A1" received the routine care provided by hospital while group "B1" received the routine care in addition to nursing care, instructions, and lower extremity strength and balance exercises by researchers. Both groups were followed up for 6 months.

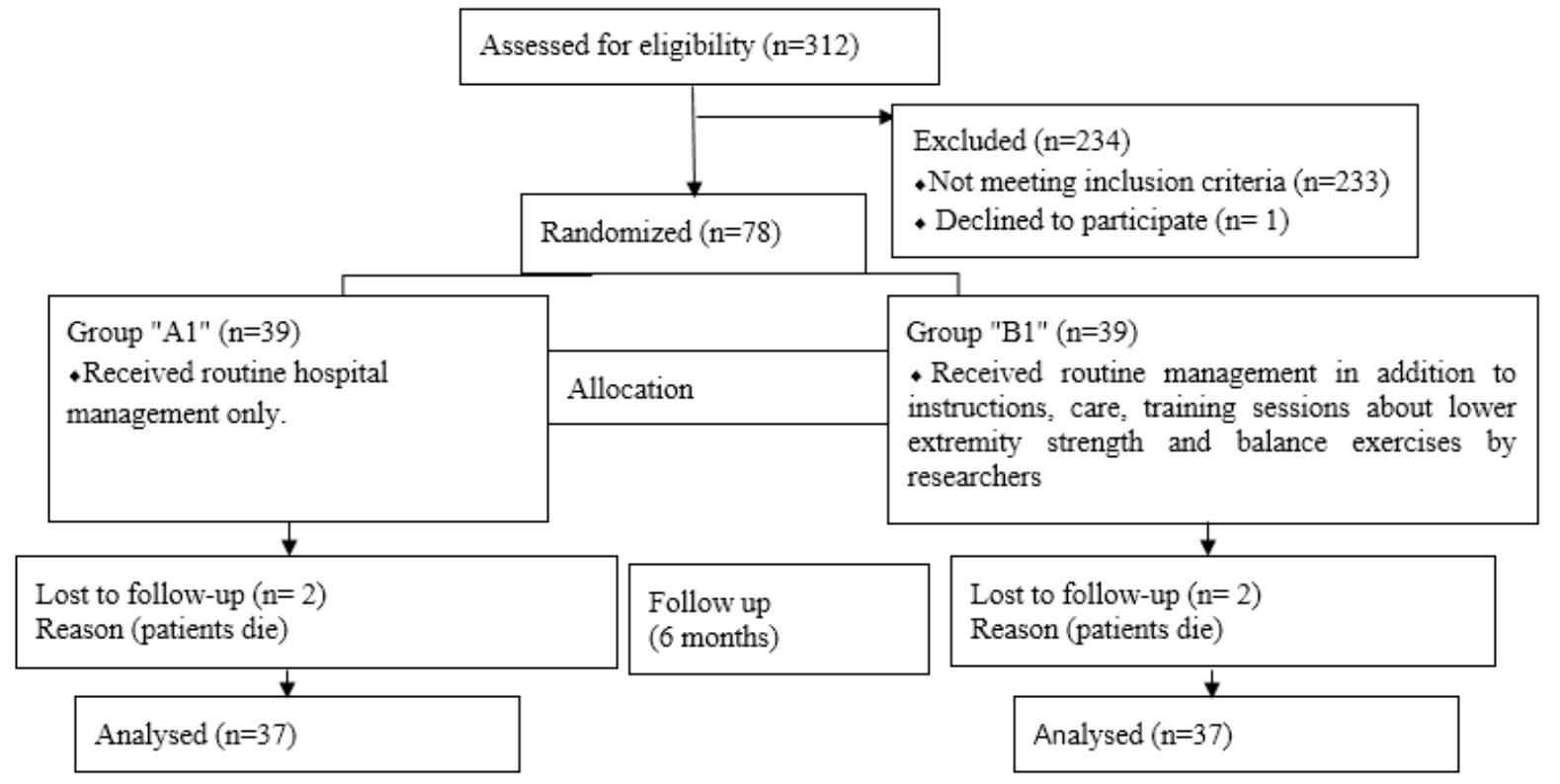

Flow diagram of patients recruitment

Tools

Tool I: Assessment sheet for patients with adult hydrocephalus planned for treatment with ventriculoperitoneal shunt

We developed patients` assessment sheet to assess patients' demographic data, Glasgow Coma Scale (Teasdale and Jennette, 1974), type of adult hydrocephalus, clinical presentations, diagnostic studies, past history of trauma, comorbidities and previous neurosurgery.

\section{Tool II: Patients` knowledge assessment questionnaire}

After reviewing different literature, we designed a knowledge assessment questionnaire to assess patients' knowledge about adult hydrocephalus and ventriculoperitoneal shunt. This questionnaire included 26 questions (2 definitions, 2 list "4 answers were required for each list question", 10 multiple choices and 12 true or false) with a maximum score of 32 . The questions concerning definition of hydrocephalus and ventriculoperitoneal shunt, types, causes, clinical presentations, diagnostic studies and complications of adult hydrocephalus, function of ventriculoperitoneal shunt, care of ventriculoperitoneal shunt at home, incision care, medications, nutrition, activity and exercises and signs and symptoms of wound infection and shunt malfunction.

One score was given for each correct answer. Total score (32). Unsatisfactory level (less than $60 \%$ ). Satisfactory level (60\% and above).

\section{Tool III: Japanese Normal Pressure Hydrocephalus Grading Scale}

It was developed by (Kubo et al., 2008) to classify a triad of disorders (gait disturbance, cognitive impairment and urinary disturbance) of 
normal pressure hydrocephalus with a wide range of severity. Minimum score (0) and maximum score (12), high score indicate more severe clinical symptoms.

Tool IV: Rand short form 36 items questionnaire (8 domains plus 1 health comparison question)

It was developed by (Ware and Sherbourne, 1992) to measure quality of life. Arabic version was used in this study (Al Abdulmohsin et al., 1997). A scale from 0-100 was using to score questions, high score indicate improved outcome.

\section{Tool V: Instructions and exercises logbook}

It was developed by researchers and consisted of instructions page and exercises page for each week over 12 weeks. Self-reported adherence of patients in the form of complete adherence $=2$, partial adherence $=1$ and non-adherence $=0$.

\section{Teaching Booklet for Patients}

Our teaching booklet consisted of Arabic information. In designing the information of our booklet we were guided by other similar booklets from University Hospital Southampton and Hydrocephalus Association (University Hospital Southampton Foundation Trust, 2017; Hydrocephalus Association, 2010; Shastin et al., 2016). The booklet content:

- Diagram of the anatomy of the brain ventricular system.

- Illustrated description of ventriculoperitoneal shunt procedure.

- Information regarding preparations prior to ventriculoperitoneal shunt procedure.

- Complications and clinical manifestations of malfunctioning shunt.

- Postoperative information about:

- Medications

- Incision care

- Care of shunt at home

- Activity

- Rest

- Sleep

- Bathing

- Driving

- Return to work

- Body weight
- Follow up.

- Lower extremity strength and balance exercises with illustrated photos.

- Standardized physical training instructions to enable patients to train by their own.

- Directions to the location of facility and contact information.

The local ethical committee was given us official approval to conduct our study. Also, patients were given us informed consent after explaining our study aim.

Three experts from 2 departments (1 medicalsurgical nursing and 2 neurosurgery staff) were engaged to review validity of the content; our study tools and teaching booklet. They were valid and reliable; Cronbach's alpha coefficient was used to assess reliability (0.84). Pilot study was done on $(10 \%)$ of patients from each group. No changes done, so those patients were included in our study.

Patients meeting inclusion criteria were visited immediately by researchers after admission. Researchers explained to the patients the aim of the study and asked the patients if they want to participate in the study or not. Patient who refused participation in our study was excluded.

During preoperative period both groups were assessed for their clinical presentations, neurological status, personal habits, comorbidities, any medications taken, diagnostic studies, history of head trauma and previous neurosurgery. Also, patients were assessed for their knowledge about adult hydrocephalus and ventriculoperitoneal shunt.

Group "A1" received the routine preoperative care and instructions provided by hospital while group "B1" received the routine preoperative care and instructions in addition to instructions by researchers (teaching booklet). Researchers explained to patients of group "B1" and their caregivers the meaning of adult hydrocephalus, causes, types, clinical manifestations, diagnosis and complications. Also, researchers explained the meaning of ventriculoperitoneal shunt, its shape, function, complications and signs and symptoms of shunt malfunction. In addition, researchers explained information concerning postoperative medications, incision care, care of shunt at home, activity, rest, sleep, bathing, driving, return to work, and physical training exercises. Follow up appointments were discussed to confirm that ventriculoperitoneal 
shunt functioning properly and for the purpose of monitoring patients` prognosis.

During postoperative period, group "A1" received the routine care and instructions provided by hospital while group "B1" received the routine care and instructions in addition to care and instructions by researchers. Nursing management aimed to reduce anxiety, relieve postoperative pain, maintain patient's safety, prevent/reduce potential complications, improve gait and cognitive abilities, promote home care and improve quality of life.

Postoperative care provided by researchers: patients placed on the unaffected side; head turned off from the incision site. Some patients placed on the back with the head of the bed elevated 30 degrees to attenuate fast drainage of cerebrospinal fluid. In addition to prescribed analgesic, proper positioning aid in relieving postoperative pain.

Clinical presentations of increased intracranial pressure were monitored to rule out shunt failure. Vital signs and neurological status were monitored, dressings over the shunt sites were inspected, and wound care was performed following aseptic technique. Incision sites were inspected for any manifestations of infection or for drainage. Patients`abdomens were assessed for any manifestations of ileus. Ventriculoperitoneal shunt valve pumped only when recommended by the neurosurgeons [applied pressure to the valve (specific reservoir site) to ensure effective functioning]. The skin along the length of the tube was observed. Patients were observed for signs and symptoms of shunt malfunction. Any unusual signs and symptoms notified to neurosurgeons immediately and appropriate actions were taken.

Patients were encouraged to ambulate early and gradually with minimal physical assistance provided by researchers during first postoperative day. Lower extremity strength and balance exercises were explained to patients and their caregivers with illustrated photos (teaching booklet) and patients trained to perform it under supervision of researchers during postoperative period. These exercises aimed to increase lower extremity strength to assist with mobility, maintain balance and prevent falling.

Lower extremity strength and balance exercises included heel raises, squats, seated marching, knee extension and knee to chest. Lower extremity strength and balance exercises were done and increasing gradually as tolerated. Patients were informed about the importance of quality rather than quantity when performing these exercises. Lower extremity strength and balance exercises were recommended for home physical training for 12 weeks. Patients were trained by researchers to do these exercises by their own in addition to standardized physical training instructions presented in the teaching booklet to enable them to train by their own.

In addition to lower extremity strength and balance exercises, gait training with walker was performed for patients with gait disturbances and unable to walk independently. Distance walked was initiated at 50 feet with minimal physical assistance provided. Distance walked was increased gradually and as tolerated.

Patients and their caregivers were educated and trained through 6 sessions. Two sessions concerning knowledge about adult hydrocephalus and ventriculoperitoneal shunt. Each session lasted 1 hour. Four exercises training sessions concerning lower extremity strength and balance exercises. Each session lasted 1 hour. Knowledge and symptoms of both groups "A1" and "B1" were evaluated before discharge.

Patients were followed up in neurosurgery outpatient clinic and by phone to follow their progression, early detection of complications and ensure continuity of home physical training exercises. Lower extremity strength and balance exercises were done by patients of group "B1" at home under supervision of their caregivers (each exercise repeated 10 times). Exercises were done twice a week for 1 hour through 12 weeks.

The design of the instructions and exercises logbook enabled patients of group "B1" to rate their weekly notes regarding their adherence to instructions and exercises. Self-reported adherence to instructions and activities was reported to researchers every week for a period of 12 weeks by phone or attendance of patient to neurosurgery outpatient clinic.

Some patients reported clinical manifestations indicate shunt malfunction/ shunt infection by phone, researchers advised them to go to hospital immediately and they observed by researchers and received appropriate management (shunt revision and antibiotic).

Postoperative complications were assessed for all patients during hospitalization and for 6 months period. After 6 months all patients [groups "A1" 
and "B1"] were presented at outpatient clinic of neurosurgery to reevaluate their knowledge, clinical presentations and Japanese Normal Pressure Hydrocephalus Grading Scale. Quality of life was assessed after 6 months. Complications were assessed immediately postoperative and through a period of 6 months.

\section{Statistical Analysis}

The data were tested for normality using the Anderson-Darling test and for homogeneity variances prior to further statistical analysis. Categorical variables were described by number and percent while continuous variables described by mean and standard deviation. We compared between categorical variables using Chi-square test and fisher exact test. We compared between continuous variables using ttest and Mann-Whitney test. Kruskal-Wallis test was used to determine if there are statistical significant differences between two or more groups of an independent variable on a continuous or ordinal dependent variable. $\mathrm{P}$ value of $<0.05$ was considered statistically significant. Statistical analysis was performed with the IBM SPSS 20.0 software.

\section{Results}

Groups "A1" and "B1" were matched and nonstatistical significant differences were found between the two groups regarding any of the demographic characteristics or baseline assessment except for length of hospital stay.
Twenty-three $(62.2 \%)$ of group "A1" and 21 (56.8\%) of group "B1" were males. The mean age was (42.16 \pm 17.01 years) for group "A1" and $(41.86 \pm 17.59$ years) for group "B1". The mean postoperative length of hospital stay for groups "A1" and "B1" was 7.78 \pm 4.08 and $6 \pm 3.34$ days respectively with statistical significant difference (p. value 0.043). More than half of patients of both groups diagnosed with idiopathic normal pressure hydrocephalus followed by idiopathic and then communicating type. Two (5.4\%) patients from each group were having diabetes mellitus and 1 patient $(2.7 \%)$ of group "A1" and $3(8.1 \%)$ of group "B1" were having hypertension. The mean Glasgow Coma Scale for groups "A1" and "B1" was 14.89 \pm 0.84 and $14.95 \pm 0.81$ respectively. Non- statistical significant differences were found between the two groups of patients regarding age, sex, type of hydrocephalus, comorbidities, Grading Scale of Japanese Normal Pressure Hydrocephalus and Glasgow Coma Scale at the baseline assessment (p. value $0.941,0.636,0.599,0.588,0.947$, $0.780)$ respectively.

Non-statistical significant differences were found between both groups of patients regarding clinical presentations preoperative (baseline assessment), postoperative (before discharge) and during follow up (after 6 months) except for nausea; statistical significant difference ( $\mathrm{p}$. value 0.03 ) was found between groups "A1" and "B1" regarding nausea during follow up (Table 1).

Table1. Clinical presentations of the studied groups

\begin{tabular}{|c|c|c|c|c|c|c|c|c|c|c|c|c|c|c|c|}
\hline \multirow{3}{*}{$\begin{array}{l}\text { Clinical } \\
\text { presentations } \\
\text { (More than } \\
\text { one) } \\
\end{array}$} & \multicolumn{4}{|c|}{$\begin{array}{l}\text { Preoperative } \\
\text { (Baseline assessment) }\end{array}$} & \multirow{3}{*}{ P. value } & \multicolumn{4}{|c|}{$\begin{array}{l}\text { Postoperative } \\
\text { (Before discharge) }\end{array}$} & \multirow[t]{3}{*}{$\begin{array}{l}\text { P. } \\
\text { value }\end{array}$} & \multicolumn{4}{|c|}{$\begin{array}{l}\text { Follow up } \\
\text { (After } 6 \text { months) }\end{array}$} & \multirow[t]{3}{*}{$\begin{array}{l}\text { P. } \\
\text { value }\end{array}$} \\
\hline & \multicolumn{2}{|c|}{$\begin{array}{l}\text { Group } \\
\text { "A1" } \\
(\mathrm{n}=37)\end{array}$} & \multicolumn{2}{|c|}{$\begin{array}{l}\text { Group } \\
\text { "B1" } \\
(\mathbf{n}=37)\end{array}$} & & \multicolumn{2}{|c|}{$\begin{array}{l}\text { Group } \\
\text { "A1" } \\
(\mathbf{n}=37) \\
\end{array}$} & \multicolumn{2}{|c|}{$\begin{array}{l}\text { Group } \\
\text { "B1" } \\
(\mathrm{n}=37)\end{array}$} & & \multicolumn{2}{|c|}{$\begin{array}{l}\text { Group } \\
\text { "A1" } \\
(\mathbf{n}=37)\end{array}$} & \multicolumn{2}{|c|}{$\begin{array}{l}\text { Group } \\
\text { "'B1" } \\
(\mathrm{n}=37)\end{array}$} & \\
\hline & No. & $\%$ & No. & $\%$ & & No. & $\%$ & No. & $\%$ & & No. & $\%$ & No. & $\%$ & \\
\hline Vomiting & 6 & 16.2 & 7 & 18.9 & 0.54 & - & - & - & - & - & 14 & 37.8 & 6 & 16.2 & 0.07 \\
\hline Headache & 37 & 100 & 37 & 100 & 1.00 & 11 & 29.7 & 8 & 21.6 & 0.595 & 23 & 62.2 & 14 & 37.8 & 0.06 \\
\hline Nausea & 3 & 8.1 & 1 & 2.7 & 0.30 & - & - & - & - & - & 11 & 29.7 & 3 & 8.1 & $0.03 *$ \\
\hline Blurred vision & 8 & 21.6 & 8 & 21.6 & 1.00 & 2 & 5.4 & 3 & 8.1 & 0.999 & 15 & 40.5 & 7 & 18.9 & 0.07 \\
\hline $\begin{array}{l}\text { Impaired } \\
\text { vision }\end{array}$ & 6 & 16.2 & 8 & 21.6 & 0.55 & 6 & 16.2 & 8 & 21.6 & 0.767 & 12 & 32.4 & 13 & 35.1 & 0.09 \\
\hline $\begin{array}{|ll|}\text { Difficult in } \\
\text { waking up }\end{array}$ & 15 & 40.5 & 15 & 40.5 & 1.00 & - & - & - & - & - & 3 & 8.1 & 2 & 5.4 & 0.643 \\
\hline
\end{tabular}

$* P<0.05$

Figure1. Unsatisfactory level of knowledge had found at assessment in groups "A1" and "B1". Our results illustrated highly statistical significant difference $(P$. value $<0.001)$ between total mean score of patients' knowledge (groups "A1" and "B1") before discharge and after 6 months. All patients of group "A1" had unsatisfactory level of knowledge before discharge and after 6 months. The majority of patients of group "B1" had satisfactory level of knowledge before discharge and after 6 months. 
Ventriculoperitoneal Shunt: Impact of Nursing Management on Outcomes of Patients with Adult Hydrocephalus

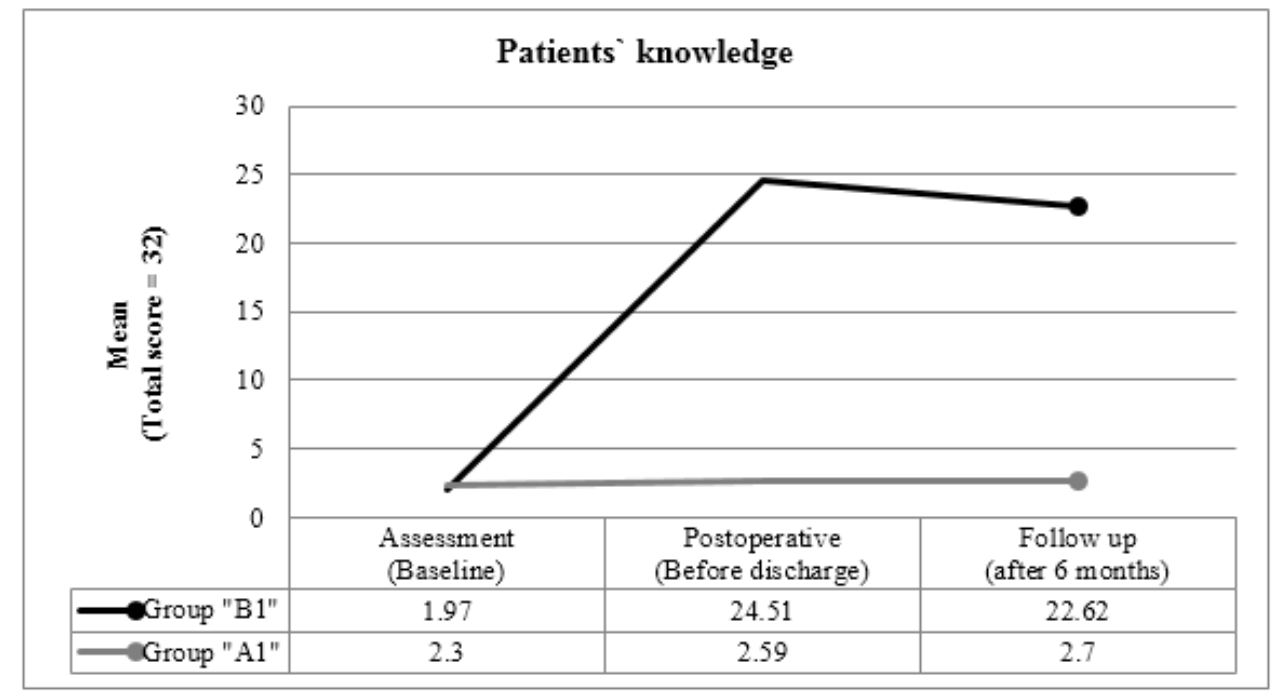

Figure1. The mean of patients` knowledge of groups "AI" and "BI" during assessment, before discharge and at the end of follow up

Statistical significant differences were found between total score of Japanese Normal Pressure Hydrocephalus Grading Scale (groups "A1" and "B1") during postoperative (before discharge) and follow up periods (P. value 0.040, 0.019)

Table2. Grading Scale of Japanese Normal Pressure Hydrocephalus of studied groups

\begin{tabular}{|l|l|l|l|}
\hline $\begin{array}{l}\text { Grading Scale of Japanese Normal Pressure } \\
\text { Hydrocephalus }\end{array}$ & $\begin{array}{l}\text { Group "A1" } \\
\text { (n=37) }\end{array}$ & $\begin{array}{l}\text { Group "B1" } \\
\text { (n=37) }\end{array}$ & P. value \\
\cline { 2 - 3 } & Mean \pm SD & Mean \pm SD & \\
\hline Preoperative (Baseline assessment) & $1.27 \pm 1.33$ & $1.27 \pm 1.41$ & 0.916 \\
\hline Gait disturbance & $0.81 \pm 0.74$ & $0.68 \pm 0.71$ & 0.425 \\
\hline Cognitive impairment & $0.3 \pm 0.74$ & $0.41 \pm 0.83$ & 0.683 \\
\hline Urinary incontinence & $2.38 \pm 2$ & $2.35 \pm 1.84$ & 0.947 \\
\hline Total & $1.57 \pm 1.09$ & $0.95 \pm 1.15$ & $0.011^{*}$ \\
\hline Postoperative (Before discharge) & $0.78 \pm 0.75$ & $0.43 \pm 0.73$ & $0.024^{*}$ \\
\hline Gait disturbance & $0.27 \pm 0.73$ & $0.41 \pm 0.83$ & 0.506 \\
\hline Cognitive impairment & $2.62 \pm 1.89$ & $1.78 \pm 1.77$ & $0.040^{*}$ \\
\hline Urinary incontinence & \multicolumn{3}{|l|}{} \\
\hline Total & $1.38 \pm 1.26$ & $0.7 \pm 1.1$ & $0.009^{* *}$ \\
\hline Follow up (After 6 months) & $0.49 \pm 0.65$ & $0.22 \pm 0.53$ & $0.028^{*}$ \\
\hline Gait disturbance & $0.62 \pm 1.04$ & $0.24 \pm 0.6$ & 0.122 \\
\hline Cognitive impairment & $2.49 \pm 2.48$ & $1.16 \pm 1.55$ & $0.019^{*}$ \\
\hline Urinary incontinence & & \\
\hline Total &
\end{tabular}

respectively. Group "B1" showed significant improvements in gait and cognitive function before discharge and at the end of follow up (after 6 months) (Table 2).

$P<0.05, * * P<0.001$

Our study results found statistical significant difference between groups "A1" and "B1" regarding postoperative complications ( $\mathrm{p}$. value 0.035). Postoperative complications were found in $22(59.5 \%)$ of group "A1" and $12(32.4 \%)$ of group "B1". Statistical significant relation was found between wound infection and shunt infection in groups "A1" and "B1"; patients who suffered from wound infection also suffered from shunt infection (p. value <0.001, 0.002 respectively).
Our study results found statistical significant difference between groups "A1" and "B1" regarding wound infection and shunt infection ( $\mathrm{p}$. value 0.022$)$. Two (5.4\%) patients of group "A1" suffered from over drainage combined with subdural hematoma and $1(2.7 \%)$ patient of group "B1" suffered from over drainage combined with subdural hematoma. Non- statistical significant differences were found between groups "A1" and "B1" regarding shunt malfunction caused by shunt obstruction, over drainage, under drainage, CSF ascites, lost distal catheters, subdural 
Ventriculoperitoneal Shunt: Impact of Nursing Management on Outcomes of Patients with Adult Hydrocephalus

hematoma and peritonitis (p. value $0.744,0.556$, $0.556,0.556,0.162,0.556,0.314$ respectively).

Highly statistical significant difference (p. value $<0.001$ ) between groups "A1" and "B1" was

Table3. Comparison between studied groups according to quality of life components after 6 months

\begin{tabular}{|l|l|l|l|}
\hline Quality of life components & $\begin{array}{l}\text { Group "A1" } \\
(\mathbf{n}=37)\end{array}$ & $\begin{array}{l}\text { Group "B1" } \\
(\mathbf{n}=\mathbf{3 7})\end{array}$ & \multirow{2}{*}{ P. value } \\
\cline { 2 - 4 } & Mean \pm SD & Mean \pm SD & \\
\hline Physical component score: & $171.62 \pm 114.74$ & $266.89 \pm 111.81$ & $<0.001^{* *}$ \\
\hline General health perception & $43.24 \pm 27.42$ & $68.24 \pm 28.04$ & $<0.001^{* *}$ \\
\hline Physical functioning & $43.92 \pm 30.28$ & $66.89 \pm 30.08$ & $0.001^{* *}$ \\
\hline Role limitations-physical & $41.89 \pm 28.9$ & $66.89 \pm 29.49$ & $<0.001^{* *}$ \\
\hline Pain & $45.57 \pm 31.11$ & $64.86 \pm 27.3$ & $0.002^{* *}$ \\
\hline Mental component score: & $161.49 \pm 115.56$ & $246.62 \pm 111.98$ & $<0.001^{* *}$ \\
\hline Vitality & $40.54 \pm 27.86$ & $64.19 \pm 27.35$ & $<0.001^{* *}$ \\
\hline Social functioning & $40.54 \pm 31.92$ & $60.81 \pm 29.19$ & $0.007^{* *}$ \\
\hline Mental health & $37.16 \pm 30.4$ & $60.81 \pm 29.19$ & $0.001^{* *}$ \\
\hline Role limitations-emotional & $43.24 \pm 29.84$ & $60.81 \pm 30.36$ & $0.015^{*}$ \\
\hline
\end{tabular}

$* P<0.05, * * P<0.001$

Figure 2. Clarified highly statistical significant difference regarding the postoperative health comparison question after 6 months between groups "A1" and "B1". Majority of group "B1" $30(81.1 \%)$ showed health improvement [8 $(21.6 \%)$ much better improvement and 22 found regarding the means of the physical and mental components of the short form 36 items questionnaire after 6 months (Table 3).
$(59.5 \%)$ somewhat better improvement]. Nineteen $(51.3 \%)$ of group "A1" showed health improvement [2 5 (5.4\%) much better improvement, $17(45.9 \%)$ somewhat better improvement].

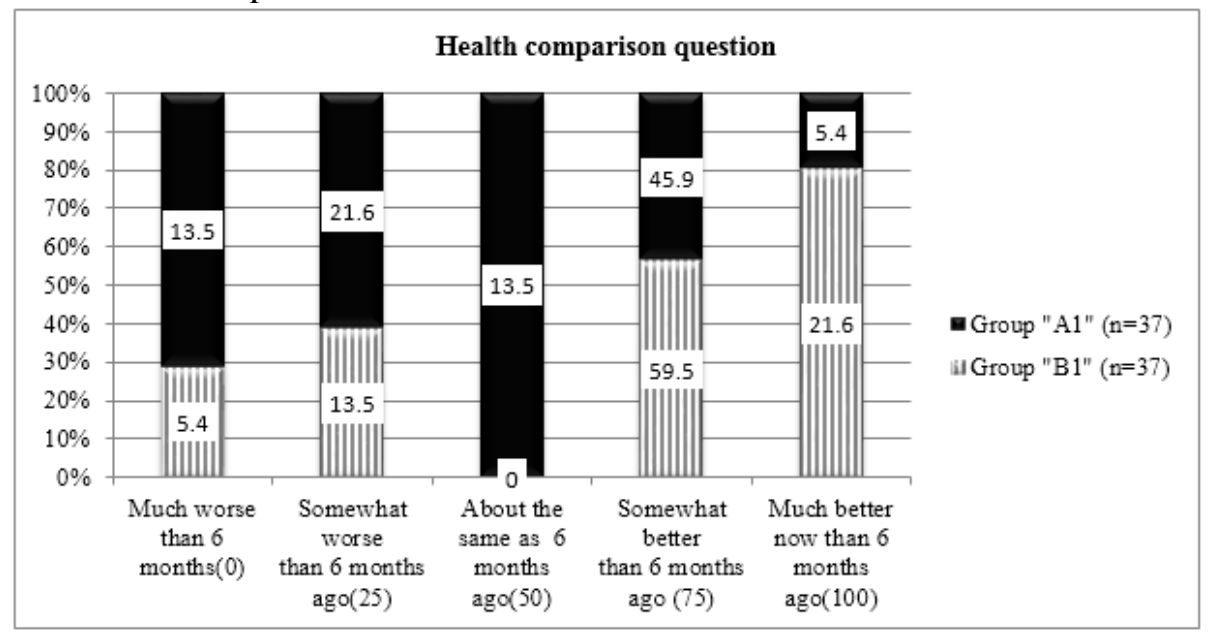

Figure2. Health changes of groups "A1" and "B1" after 6 months

Our study results showed non-statistical significant relations between patients' ages (groups "A1" and "B1") and physical (p. value $0.315,0.324$ ) and mental (p. value $0.365,0.542$ ) components scores of the short form 36 items questionnaire respectively. Also, non-statistical significant relation was found as regard health comparison question $(0.167,0.419)$ respectively.

Our study results showed non-statistical significant relations between types of hydrocephalus (groups "A1" and "B1") and physical (p. value $0.332,0.185$ ) and mental (p. value $0.758,0.373)$ components scores of the short form 36 items questionnaire respectively.
Also, non-statistical significant relation was found as regard health comparison question $(0.816,0.148)$ respectively.

Our study results showed non-statistical significant relations between comorbidities (groups "A1" and "B1") and physical (p. value $0.819,0.808$ ) and mental (p. value $0.871,0.834$ ) components scores of the short form 36 items questionnaire respectively. Also, non-statistical significant relation was found as regard health comparison question $(0.608,0.754)$ respectively.

We found highly statistical significant relation in both groups of patients between postoperative 
Ventriculoperitoneal Shunt: Impact of Nursing Management on Outcomes of Patients with Adult Hydrocephalus

complications and the physical and mental components plus health comparison question of the short form 36 items questionnaire (p. value $<0.001)$.

Figure 3. Illustrated that twenty two (59.5\%) patients of group "B1" completely adhere to instructions and 15 (40.5\%) patients partially adhere to instructions. More than two-third 26 $(70.27 \%)$ of patients of group "B1" completely adhere to lower extremity strength and balance exercises and 11(29.7\%) patients partially adhere to lower extremity strength and balance exercises.

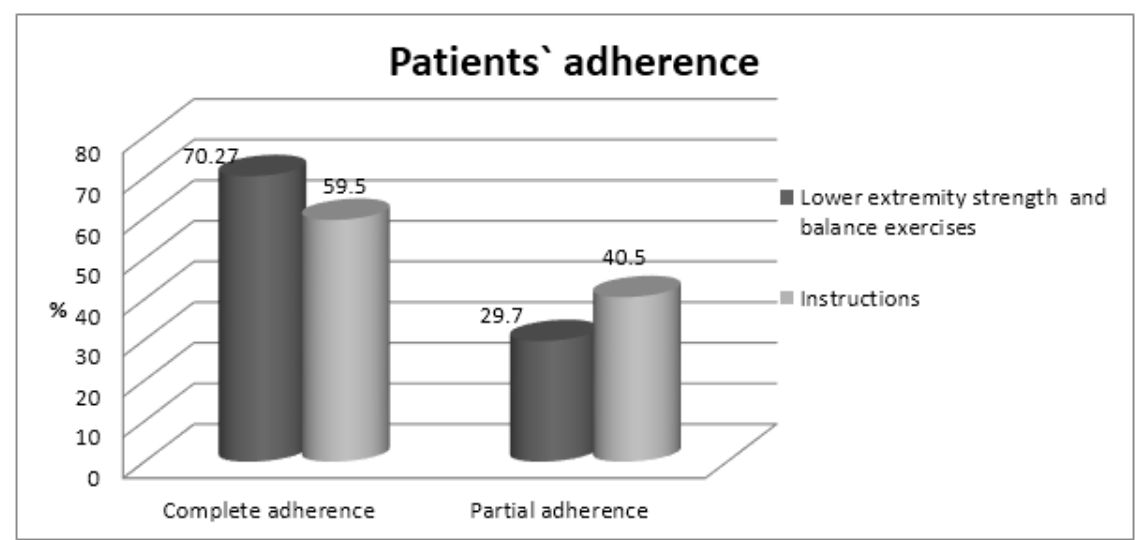

Figure3. Adherence of patients of group "B1" to instructions and lower extremity strength and balance exercises

We found highly statistical significant relations between complete adherence to exercises and the physical and mental components plus health comparison question of the short form 36 items questionnaire. Also, our results found statistical

Table4. Relationship between quality of life components and adherence to exercises and instructions after 6 months for group "BI"

\begin{tabular}{|c|c|c|c|c|c|c|}
\hline \multirow{3}{*}{$\begin{array}{l}\text { Quality of life } \\
\text { components }\end{array}$} & \multicolumn{3}{|c|}{ Exercises } & \multicolumn{3}{|c|}{ Instructions } \\
\hline & $\begin{array}{c}\text { Partial } \\
\text { adherence } \\
(n=11)\end{array}$ & $\begin{array}{c}\text { Complete } \\
\text { adherence } \\
(n=26)\end{array}$ & \multirow[t]{2}{*}{ P. value } & $\begin{array}{c}\text { Partial } \\
\text { adherence } \\
(n=15)\end{array}$ & $\begin{array}{c}\text { Complete } \\
\text { adherence } \\
(\mathbf{n}=22)\end{array}$ & \multirow[t]{2}{*}{ P. value } \\
\hline & Mean \pm SD & Mean \pm SD & & Mean \pm SD & Mean \pm SD & \\
\hline $\begin{array}{l}\text { Physical component } \\
\text { score }\end{array}$ & $143.18 \pm 119.94$ & $319.23 \pm 51.63$ & $<0.001 * *$ & $201.67 \pm 144.07$ & $311.36 \pm 49.84$ & $0.017 *$ \\
\hline $\begin{array}{l}\text { Mental component } \\
\text { score }\end{array}$ & $134.09 \pm 112.51$ & $294.23 \pm 71.17$ & $0.001 * *$ & $185 \pm 134.23$ & $288.64 \pm 70.17$ & $0.022 *$ \\
\hline $\begin{array}{l}\text { Health comparison } \\
\text { question }\end{array}$ & $38.64 \pm 30.34$ & $82.69 \pm 11.77$ & $<0.001 * *$ & $53.33 \pm 36.43$ & $80.68 \pm 10.72$ & $0.002 * *$ \\
\hline
\end{tabular}

significant relations between complete adherence to instructions and physical and mental components plus health comparison question of the short form 36 items questionnaire (Table 4).

$* P<0.05$, ** $P<0.001$

Highly statistical significant relation was found between total score of Grading Scale of Japanese Normal Pressure Hydrocephalus and complete adherence to exercises (gait improvement). Statistical significant relation was found between gait improvement and complete adherence to instructions (Table 5).

Table5. Relationship between Grading Scale of Japanese Normal Pressure Hydrocephalus and adherence to exercises and instructions after 6 months for group "B1"

\begin{tabular}{|c|c|c|c|c|c|c|}
\hline \multirow{3}{*}{$\begin{array}{l}\text { Grading Scale of } \\
\text { Japanese Normal } \\
\text { Pressure } \\
\text { Hydrocephalus }\end{array}$} & \multicolumn{2}{|c|}{ Exercises } & \multirow[t]{3}{*}{ P.value } & \multicolumn{2}{|c|}{ Instructions } & \multirow[t]{3}{*}{ P.value } \\
\hline & $\begin{array}{c}\text { Partial } \\
\text { adherence } \\
(\mathbf{n}=\mathbf{1 1})\end{array}$ & $\begin{array}{c}\begin{array}{c}\text { Complete } \\
\text { adherence } \\
(\mathbf{n}=\mathbf{2 6})\end{array} \\
\end{array}$ & & $\begin{array}{c}\text { Partial } \\
\text { adherence } \\
(\mathbf{n}=\mathbf{1 5})\end{array}$ & \begin{tabular}{|c}
$\begin{array}{c}\text { Complete } \\
\text { adherence } \\
(\mathbf{n}=\mathbf{2 2})\end{array}$ \\
\end{tabular} & \\
\hline & Mean \pm SD & Mean \pm SD & & Mean \pm SD & Mean \pm SD & \\
\hline Gait disturbance & $1.73 \pm 1.27$ & $0.27 \pm 0.67$ & $0.001 * *$ & $1.27 \pm 1.33$ & $0.32 \pm 0.72$ & $0.023 *$ \\
\hline Cognitive impairment & $0.36 \pm 0.81$ & $0.15 \pm 0.37$ & 0.678 & $0.27 \pm 0.7$ & $0.18 \pm 0.39$ & 0.847 \\
\hline Urinary incontinence & $0.45 \pm 0.93$ & $0.15 \pm 0.37$ & 0.353 & $0.33 \pm 0.82$ & $0.18 \pm 0.39$ & 0.820 \\
\hline Total & $2.55 \pm 1.86$ & $0.58 \pm 0.95$ & $0.001 * *$ & $1.87 \pm 1.96$ & $0.68 \pm 0.99$ & 0.071 \\
\hline
\end{tabular}

$* P<0.05, * * P<0.001$ 


\section{DISCUSSION}

Our study provided data about impact of nursing management on short-term prognosis of patients after insertion of ventriculoperitoneal shunt to treat adult hydrocephalus.

In our study, more than half of patients in groups ("A1 and "B1") were males, diagnosed with idopathic normal pressure hydrocephalus with mean age $38.52 \pm 15.84$ years of group "A1" and $42.16 \pm 17.01$ years of group "B1".

This similar to study conducted on 227 adult patients diagnosed with hydrocephalus and treated by ventriculoperitoneal shunt with mean age 45.8 years and more than half of them were males (Anderson and Chumas, 2012). The most common type of adult hydrocephalus is the idopathic normal pressure hydrocephalus (Williams and Malm, 2016).

Clinical improvement was observed in the majority of patients as regarding clinical manifestations (vomiting, headache, nausea, seizures, blurred vision, irritability and difficult in waking up) during the first postoperative days after insertion of ventriculoperitoneal shunt. During follow up period, some patients reported some of these manifestations.

This early improvement showed the effect of ventriculoperitoneal shunt; equalize pressure of CSF and minimize/prevent manifestations of increased intracranial pressure (Sotelo, 2012). All symptoms of idiopathic normal pressure hydrocephalus can improve after ventriculoperitoneal shunt (Williams and Malm, 2016).

Some patients may experience temporary improvement. The success rate of ventriculoperitoneal shunt varies from patient to patient. Some patients recover completely after ventriculoperitoneal shunt insertion and have a good quality of life. Also, early diagnosis and treatment improves the chance of a good prognosis (National Institutes of Health, 2010).

The occurrence of previous preoperative manifestations or manifestations of increased intracranial pressure during follow up period could be as a result of shunt complications. In our study some patients were experienced some postoperative complications including wound infection, shunt malfunction, over drainage, under drainage, lost distal catheter and subdural hematoma. Malfunctioning shunt is the most common complication of shunt caused by shunt infection or obstruction or both. Significant relation was found between wound infection and shunt infection. Shunt revisions were done for all patients with malfunctioning shunts during follow up period (6 months).

In the same line, study reported that complications of ventriculoperitoneal shunt involve complications related to the shunt system or complications reflected in overall suboptimal ventriculoperitoneal shunt function. Complications include but not limited to shunt malfunction, shunt infection, subdural hematoma, seizure and intracerebral hematoma. Shunt infection is the most common complication and has been reported to appear in a large number of patients. Shunt dysfunction can lead to increase CSF pressure, which may lead to recurrence of original adult hydrocephalus manifestations (National Institutes of Health, 2010). Shunt revisions were done for patients with malfunctioning shunts and the majority of shunt revisions occurred within the first 6 months (Reddy et al., 2011).

Symptomatic benefits offered by ventriculoperitoneal shunt were partial and transient; ventriculoperitoneal shunt was associated with high complications rate and poor functional outcome in the long-term (Illán-Gala et al., 2017).

In our study, shunt complications were found to have a negative impact on quality of life (physical and mental components plus health comparison question).

On contrary to this result, other study reported that shunt complication (shunt malfunction) was not found to have a significant impact on the overall functional outcome of patients (Khan et al., 2015).

In our study, age of patients, type of hydrocephalus and the presence of comorbidities; diabetes or hypertension were found to have no negative impact on the quality of life of patients.

Similar results, type of hydrocephalus have no negative impact on outcome of patients (Merkler et al., 2017). Vascular comorbidities have no negative impact on outcome of patients (Andrén et al., 2018).

Rate of improvement following ventriculoperitoneal shunt has improved in recent years with marked reduction in mortality and morbidity 
despite the age of patients, associated comorbidities and poor mobility (Toma et al., 2013).

Unsatisfactory level of knowledge was found for all patients (groups "A1" and "B1") at the time of assessment. This could be as a result of lack of patients information; health care team didn't provide patients with enough information regarding their postoperative care, home care, instructions, physical training (lower extremity strength and balance exercises and how to use a cane if needed) and how to life with ventriculoperitoneal shunt.

Patients are in essential need for information about the disease and how to life with ventriculoperitoneal shunt to improve their outcomes (University Hospital Southampton Foundation Trust, 2017; Hydrocephalus Association, 2010).

The level of patients' knowledge was improved significantly in group "B1" before discharge and after 6 months. Also, those patients adhere to instructions and lower extremity strength and balance exercises and these led to decrease length of hospital stay, significant improvement in clinical manifestations (gait and cognitive function as regarding Grading Scale of Japanese Normal Pressure Hydrocephalus), little complications and highly significant improvement in quality of life. These significant differences could explain the impact of nursing management; care, instructions and physical training of lower extremity strength and balance exercises (teaching booklet, oral education and physical training sessions) on clinical improvement of those patients.

Before discharge and after 6 months, our study results showed significant improvement in Grading Scale of Japanese Normal Pressure Hydrocephalus (gait and cognitive function) of group "B1".

In our study, quality of life of group "B1" was significantly higher than group "A1" regarding physical and mental components scores. Concerning health comparison question (health change), the majority of group "B1" showed significant health improvement while more than half of group "A1" showed significant health improvement.

Walking and balance can improve after ventriculoperitoneal shunt insertion. Physical therapy and teach patients to use a walker or cane if needed considered essential parts in improving the outcome of patients. Many patients find physical therapy helpful after surgery to improve their balance and ability to walk. Many patients can show great improvement in walking within a few weeks after ventriculoperitoneal shunt insertion when accompanied by physical training. Memory and thinking skills are often slow to recover after ventriculoperitoneal shunt insertion (Mikesell, 2017).

Our study supported by similar results reported that statistical and clinical significant improvements were observed in functional independence, quality of life and cognition for patients received rehabilitation training combined with ventriculoperitoneal shunt (Lehnert et al., 2011). The improved outcome and reduced mortality and morbidity for patients with adult hydrocephalus might be explained by the improved hospital care and postoperative rehabilitation (Toma et al., 2013).

Lower extremity strength exercises improve the outcome of patients which had been observed before discharge and during follow up period (few weeks) (Mikesell, 2017).

Complete adherence to exercises and instructions showed significant improvements in gait, cognitive function and quality of life components than partial adherence. Exercises and instructions logbook served as a reminder and motivational track record for patients and their caregivers.

Results of (McLean et al., 2010) reported that poor adherence to the treatment plan is commonplace and affects patients' outcomes. Adherence strategy is not effective in improving long-term adherence to home exercises. Exercises logbook is an important tool for patient`s record.

\section{LIMITATION}

The level of patients' adherence to home instructions and exercises was recorded in instructions and exercises logbook and reported to researchers by the patients and their caregivers (self-reported) and not observed directly by the researchers.

\section{CONCLUSION}

Neurosurgery nurses play a vital role in ensuring positive patients` outcomes by providing nursing management that is directed at improving gait, cognition, quality of life and patients presented with no or fewer postoperative complications/ clinical presentations. 


\section{RECOMMENDATIONS}

Adult patient who performed ventriculoperitoneal shunt surgery should have periodic follow up visits. Most neurosurgery nurses and neurosurgeons have not been trained to provide longitudinal care for patients with adult hydrocephalus treated by ventriculoperitoneal shunt, they should learn and train to do so.

\section{REFERENCES}

[1] Al Abdulmohsin, S.A., Coons, S., Draugalis, J.R. and Hays, R.D., 1997. Translation of the RAND 36-item health survey 1.0 (aka SF-36) into Arabic.

[2] American Association of Neurological Surgeons, 2018. Adult-Onset Hydrocephalus. Published article. http://www.aans.org/ Patients /Neurosurgical-Conditions-and-Treatments /Adult-Onset-Hydrocephalus

[3] Anderson, I.A. and Chumas, P.D., 2012. Management of the patient with a ventriculoperitoneal shunt presenting with headache. British Journal of Hospital Medicine, 73(Sup11), pp.C170-C173.

[4] Andrén, K., Wikkelsö, C., Sundström, N., Agerskov, S., Israelsson, H., Laurell, K., Hellström, P. and Tullberg, M., 2018. Long-term effects of complications and vascular comorbidity in idiopathic normal pressure hydrocephalus: a quality registry study. Journal of neurology, 265(1), pp.178-186.

[5] Assiut University Hospital Records (2015). Neurosurgery department. Assiut Neurological, Psychiatric and Neurosurgery University Hospital. Egypt

[6] Chen, Z., Chen, G., Song, W., Liu, L., Yang, Y. and Ling, F., 2009. Rehabilitation combined with ventriculoperitoneal shunt for patients with chronic normal pressure hydrocephalus due to aneurysm subarachnoid haemorrhage: a preliminary study. Journal of rehabilitation medicine, 41(13), pp.1096-1099.

[7] Ferguson, S.D., Michael, N. and Frim, D.M., 2007. Observations regarding failure of cerebrospinal fluid shunts early after implantation. Neurosurgical focus, 22(4), pp.15.

[8] Hydrocephalus Association, 2010. About Normal Pressure Hydrocephalus: A book for Adults and their Families, San Francisco.

[9] Illan-Gala, I., Perez-Lucas, J., Martin-Montes, A., Manez-Miro, J., Arpa, J. and Ruiz-Ares, G., 2017. Long-term outcomes of adult chronic idiopathic hydrocephalus treated with a ventriculo-peritoneal shunt. Neurología (English Edition), 32(4), pp.205-212.
[10] Jaraj, D., 2016. Epidemiology of Normal Pressure Hydrocephalus-Prevalence, Risk Factors, Diagnosis and Prognosis.

[11] Jenkinson, M.D., Gamble, C., Hartley, J.C., Hickey, H., Hughes, D., Blundell, M., Griffiths, M.J., Solomon, T. and Mallucci, C.L., 2014. The British antibiotic and silver-impregnated catheters for ventriculoperitoneal shunts multicentre randomised controlled trial (the BASICS trial): study protocol. Trials, 15(1), p.4.

[12] Khan, F., Rehman, A., Shamim, M.S. and Bari, M.E., 2015. Factors affecting ventriculoperitoneal shunt survival in adult patients. Surgical neurology international, 6(1), p. 25 .

[13] Kubo, Y., Kazui, H., Yoshida, T., Kito, Y., Kimura, N., Tokunaga, H., Ogino, A., Miyake, H., Ishikawa, M. and Takeda, M., 2008. Validation of grading scale for evaluating symptoms of idiopathic normal-pressure hydrocephalus. Dementia and geriatric cognitive disorders, 25(1), pp.37-45.

[14] Lehnert, B.E., Rahbar, H., Relyea-Chew, A., Lewis, D.H., Richardson, M.L. and Fink, J.R., 2011. Detection of ventricular shunt malfunction in the ED: relative utility of radiography, CT, and nuclear imaging. Emergency radiology, 18(4), pp.299-305.

[15] McLean, S.M., Burton, M., Bradley, L. and Littlewood, C., 2010. Interventions for enhancing adherence with physiotherapy: a systematic review. Manual therapy, 15(6), pp.514-521.

[16] Merkler, A.E., Ch'ang, J., Parker, W.E., Murthy, S.B. and Kamel, H., 2017. The rate of complications after ventriculoperitoneal shunt surgery. World neurosurgery, 98, pp.654-658.

[17] Mikesell, S., 2017. Acute care rehabilitation for a patient with normal pressure hydrocephalus.

[18] Nassar, B.R. and Lippa, C.F., 2016. Idiopathic normal pressure hydrocephalus: a review for general practitioners. Gerontology and Geriatric Medicine, 2, pp. 1-6.

[19] National Institutes of Health, 2010. Hydrocephalus Fact Sheet. National Institute of Neurological Disorders and Stroke.

[20] Nelson,S.L., 2016. Hydrocephalus, Published article. WebMD LLC., https://emedicine. medscape.com/ article/1135286-overview

[21] Parsons,J.A., Seay, A.R., and Jacobson,M., 2016. Neurologic disorders. Meresenstein and Gardner's Handbook of Neonatal Intensive Care. Vol St. Louis. MO: Elsevier.

[22] Reddy, G.K., Bollam, P., Shi, R., Guthikonda, B. and Nanda, A., 2011. Management of adult hydrocephalus with ventriculoperitoneal shunts: long-term single-institution experience. Neurosurgery, 69(4), pp.774-781. 
[23] Rinker, E.K., Williams, T.R. and Myers, D.T., 2015. CSF shunt complications: what the abdominal imager needs to know. Abdominal imaging, 40(6), pp.2030-2040.

[24] Roytowski, D. and Figaji, A., 2013. Raised intracranial pressure: What it is and how to recognise it. Continuing Medical Education, 31(3), pp.85-90.

[25] Shastin, D., Zaben, M. and Leach, P., 2016. Life with a cerebrospinal fluid (CSF) shunt. BMJ: British Medical Journal, 355, p.i5209.

[26] Sivagnanam, M. and Jha, N.K., 2012. Hydrocephalus: An Overview. In Hydrocephalus. InTech.

[27] Sotelo, J., 2012. The hydrokinetic parameters of shunts for hydrocephalus might be inadequate. Surgical neurology international, 3(1), p.40.

[28] Teasdale, G. and Jennett, B., 1974. Assessment of coma and impaired consciousness: a practical scale. The Lancet, 304(7872), pp.81-84.

[29] Toma, A., 2018. Hydrocephalus in Adults. In Principles of Neurological Surgery Fourth Edition, pp. 822-831.
[30] Toma, A.K., Papadopoulos, M.C., Stapleton, S., Kitchen, N.D. and Watkins, L.D., 2013. Systematic review of the outcome of shunt surgery in idiopathic normal-pressure hydrocephalus. Acta neurochirurgica, 155(10), pp.1977-1980.

[31] University Hospital Southampton Foundation Trust (2017). Adult hydrocephalus and shunts: Information for patients. London UK. Version 1, pp. 3-14.

[32] Ware Jr, J.E. and Sherbourne, C.D., 1992. The MOS 36-item short-form health survey (SF-36): I. Conceptual framework and item selection. Medical care, pp.473-483.

[33] Williams,M.A., and Malm,J., 2016. Diagnosis and treatment of idiopathic normal pressure hydrocephalus. CONTINUUM: Lifelong Learning in Neurology. 22(2), pp. 579-599

[34] Witiw, C., Hachem, L. and Bernstein, M., 2017. Clinical Presentation of Hydrocephalus in Adults. Hydrocephalus. Springer, Cham. pp. $115-125$.

Citation: Rasha Ali Ahmed Abdelmowla, Abdelhakeem A. Essa. Ventriculoperitoneal Shunt: Impact of Nursing Management on Outcomes of Patients with Adult Hydrocephalus. ARC Journal of Nursing and Healthcare. 2019; 5(1):9-21. doi: dx.doi.org/10.20431/2455-4324.0501002.

Copyright: (C) 2019 Authors. This is an open-access article distributed under the terms of the Creative Commons Attribution License, which permits unrestricted use, distribution, and reproduction in any medium, provided the original author and source are credited. 